\title{
Critical care trainees' career goals and needs: A Canadian survey
}

\author{
Maude St-Onge MD MSc FRCPC PhD(c) ${ }^{1,2}$, Keren Mandelzweig MD FRCPC ${ }^{2}$, John C Marshall MD FRCSC ${ }^{2,3}$, \\ Damon C Scales MD FRCPC PhD ${ }^{1,2}$, John Granton MD FRCPC ${ }^{2,4}$
}

\begin{abstract}
M St-Onge, K Mandelzweig, JC Marshall, DC Scales, J Granton. Critical care trainees' career goals and needs: A Canadian survey. Can Respir J 2014;21(2):93-95.
\end{abstract}

BACKGROUND: For training programs to meet the needs of trainees, an understanding of their career goals and expectations is required.

OBJECTIVES: Canadian critical care medicine (CCM) trainees were surveyed to understand their career goals in terms of clinical work, research, teaching, administration and management; and to identify their perceptions regarding the support they need to achieve their goals.

METHODS: The online survey was sent to all trainees registered in a Canadian adult or pediatric CCM program. It documented the participants' demographics; their career expectations; the perceived barriers and enablers to achieve their career goals; and their perceptions relating to their chances of developing a career in different areas.

RESULTS: A response rate of $85 \%$ (66 of 78) was obtained. The majority expected to work in an academic centre. Only approximately one-third (31\%) estimated their chances of obtaining a position in CCM as $>75 \%$. The majority planned to devote $25 \%$ to $75 \%$ of their time performing clinical work and $<25 \%$ in education, research or administration. The trainees perceived that there were limited employment opportunities. Networking and having specialized expertise were mentioned as being facilitators for obtaining employment. They expressed a need for more protected time, resources and mentorship for nonclinical tasks during training.

CONCLUSION: CCM trainees perceived having only limited support to help them to achieve their career goals and anticipate difficulties in obtaining successful employment. They identified several gaps that could be addressed by training programs, including more mentoring in the areas of research, education and administration.

Key Words: Career; Critical care; Education; Needs assessment; Survey; Training

Tn 2009, the Community Tracking Study Physician Survey (20042005) collected cross-sectional data from 6590 physicians to measure career satisfaction. Clinicians practicing pulmonary critical care medicine (CCM) had lower career satisfaction levels than physicians in other specialties, including pediatric subspecialties, neonatal medicine, dermatology, geriatric and internal medicine (1). With recent growing awareness regarding physician burnout and fatigue, as exemplified by the current work hours restrictions in the United States and parts of Canada (Quebec), which are intended to enhance practice safety and quality of life of trainees (2), some experts have proposed increasing the number of trained intensivists, as well as implementing strategies to ensure that they will have long, fulfilling careers in CCM (3).

However, little data regarding the career goals of CCM trainees exist, specifically for those who are enrolled in Canadian training programs. Therefore, we conducted a national survey of Canadian CCM trainees to understand their career goals with regard to clinical work, research, teaching, administration and management. The study also aimed to identify the trainees' perceptions of the support they require to achieve their career goals.

\section{Les besoins et objectifs de carrière des résidents en soins intensif Canadiens}

HISTORIQUE: Afin d'aider les programmes à rencontrer les besoins des résidents, une bonne compréhension de leurs objectifs de carrière est requise.

OBJECTIFS: Nous avons conduit un sondage auprès des intensivistes canadiens en formation afin: de comprendre leurs objectifs de carrière en ce qui a trait au travail clinique, à la recherche, à l'enseignement ainsi qu'à l'administration et; d'identifier leurs perceptions en ce qui concerne le support reçu.

MÉTHODOLOGIE: Le sondage en ligne a été envoyé à tous les intensivistes adulte et pédiatrique en formation au Canada. L'étude documentait les caractéristiques démographiques des participants, leurs objectifs de carrière, les barrières et facteurs facilitant l'atteinte de leurs objectifs ainsi que leurs perceptions concernant leurs chances de développer une carrière d'intensiviste.

RÉSULTATS: Nous avons obtenu un taux de réponse de 85\% (66/78). La majorité s'attendait à travailler dans un centre académique. Seulement $31 \%$ estimait leurs chances d'obtenir une position comme étant supérieures à $75 \%$. La majorité prévoyait attribuer $25-75 \%$ de leur temps au travail clinique, $25 \%$ ou moins à l'enseignement, la recherche ou l'administration. Les intensivistes en formation ont souligné le manque de positions disponibles comme étant une barrière importante. Avoir en main une expertise particulière ou un réseau de collaborateurs furent identifiés comme facilitateurs. Les répondants ont souligné l'importance d'avoir du temps protégé, suffisamment de ressources et de mentors disponibles.

CONCLUSIONS: Les intensivistes canadiens en formation perçoivent le soutien disponible pour atteindre leurs objectifs comme étant pauvre. Ils visent obtenir un travail principalement clinique dans un centre académique.

${ }^{1}$ Sunnybrook Health Sciences Centre; ${ }^{2}$ University of Toronto; ${ }^{3} \mathrm{Li}$ Ka Shing Knowledge Institute, St Michael's Hospital; ${ }^{4}$ Toronto General Hospital, Toronto, Ontario

Correspondence: Dr Maude St-Onge, Sunnybrook Health Sciences Centre, 2075 Bayview Avenue, Room D1-08, Toronto, Ontario M4N 3M5.

Telephone 416-480-6100, e-mail egnomie@hotmail.com or stongem@smh.ca 


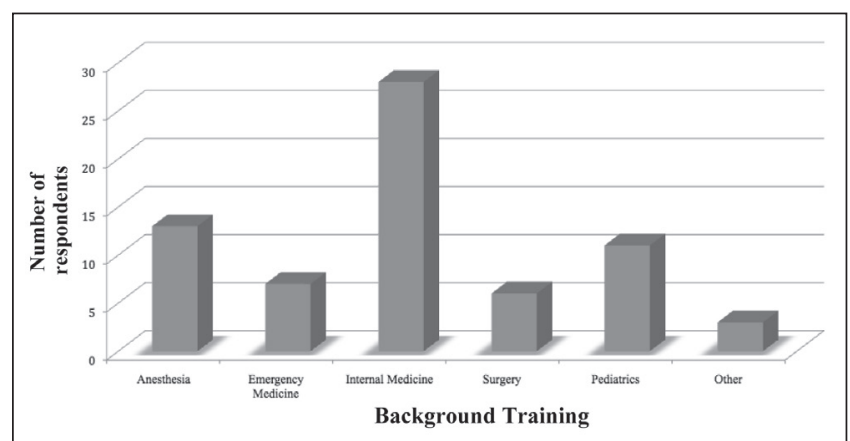

Figure 1) Background training

scholar (researcher and teacher) and manager knowing that the roles of communicator, collaborator, health advocate and professional are inherent to all career profiles (4). The survey was pretested and further refined using four trainees with different training backgrounds (emergency medicine, anesthesia, internal medicine and general surgery), residing in different provinces and speaking English, French or both. The French version of the survey was adapted from the English version and then back-translated to ensure consistency.

The final questionnaire (Appendix 1, available online at www. pulsus.com) asked respondents to estimate the proportion of their future practice that they expected to devote to the four different career profiles (clinical work, research, teaching and management). The quality of support they were receiving from their CCM training program was rated using a five-point Likert scale for each of the career profiles; barriers and enablers to achieving their goals were collected using open-ended response fields. In addition, they were asked to evaluate their perceptions of successfully obtaining employment in an intensivist position with different job characteristics using five-point Likert scales.

\section{Survey administration}

FluidSurveys (Ottawa, Ontario) was used to administer the web-based survey, which was endorsed by the Canadian Critical Care Society and the Canadian Critical Care Trials Group. An invitation to participate was sent to all program directors of Canadian CCM residency programs (adult and pediatric), asking them to forward the link for the survey to current residents. The link to the survey first directed potential respondents to a consent form and, once completed, led participants to the web-based questionnaire. Trainees not enrolled in a residency program formally accredited by the Royal College of Physicians ansd Surgeons of Canada (ie, hospital-based clinical fellowships, etc) were deemed ineligible for participation in the survey. An electronic reminder was sent every week for three consecutive weeks.

\section{Statistical analysis}

Only completed questionnaires were analyzed. Results were summarized and reported using descriptive statistics (proportions). Reported barriers were listed and enablers were grouped as statements expressing the same idea by two members of the study team. Disagreements in these groupings were resolved by consensus and a third member of the study team.

\section{Respondents' characteristics}

\section{RESULTS}

A response rate of $85 \%$ (66 of $78 ; 53$ from adult and 13 from pediatric CCM programs) was obtained. Respondents represented seven Canadian provinces: Ontario $(n=27[41 \%])$, Quebec $(n=25$ [38\%]), Manitoba $(n=5[8 \%])$, Alberta $(n=4[6 \%])$, British-Columbia $(n=3$ [5\%]), Nova Scotia $(n=1[1 \%])$ and Newfoundland and Labrador $(n=1[1 \%])$. Respondents were evenly distributed between the first $(n=32[48 \%])$ and second $(n=35[53 \%])$ year of training. Figure 1 illustrates the trainees' training background, with internal medicine being most highly represented.

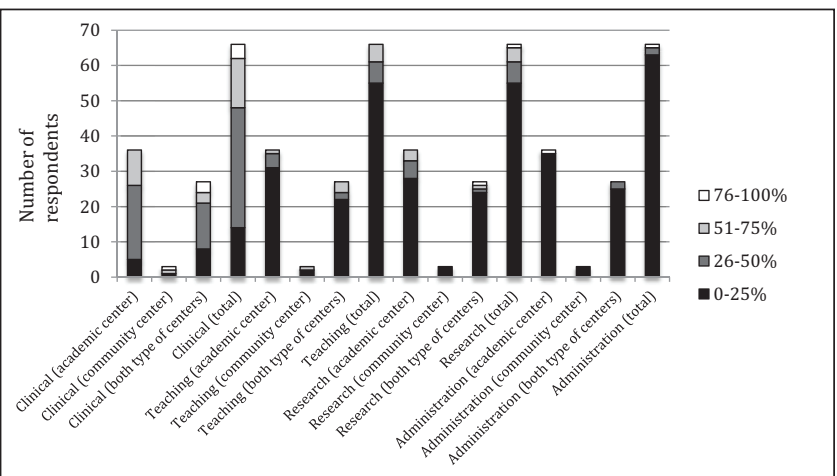

Figure 2) Proportion of work the trainees estimated to devote to clinical work, teaching, research or administration in critical care medicine depending on their career expectations

\section{Career expectations}

Nearly three-quarters (74\%) of respondents hoped to practice CCM in the province in which they trained. The majority (53\%) expected to work in an academic centre or a combination of academic and community centres (43\%). Only 4\% planned to work solely in a community setting. More than one-third of participants (38\%) were considering additional training after completion of their CCM residency. The most frequently mentioned additional training areas were research $(6 \%)$, education $(6 \%)$, neurocritical care $(6 \%)$, trauma $(3 \%)$ and ultrasound $(3 \%)$.

Most (79\%) respondents estimated their probability of finding employment as a physician to be $>75 \%$. However, only approximately one-third expected to work as an intensivist: $31 \%$ rated the probability of CCM employment to be $>75 \%$; and $33 \%$ expected the probability to be between $25 \%$ and $75 \%$. Only one-half $(48 \%)$ judged the probability of obtaining their desired job description to be $>50 \%$. Figure 2 illustrates the proportion of time the trainees expected to ultimately devote to performing clinical work, teaching, research or administration in CCM. It is noteworthy that an important proportion of trainees were planning to invest their clinical career in another field other than CCM; $47 \%(n=17)$ of trainees who were expecting to work in an academic centre, $67 \%(n=2)$ who were planning for a career in a community centre and $48 \%(n=13)$ who were planning to work in both settings were expecting to work $26 \%$ to $75 \%$ of their time outside of CCM.

Many trainees perceived that they were receiving inadequate support to develop their career goals in all four categories; clinical (fair $30 \%$, poor $31 \%$ ), education (fair $32 \%$, poor $30 \%$ ), research (fair $32 \%$, poor $32 \%$ ) and administrative (fair $21 \%$, poor $41 \%$, none $24 \%$ ) career goals.

Barriers and enablers to achieve career goals

Barriers to and enablers for achieving career goals were grouped according to the following themes: CCM training, extracurricular activities, work environment, professional network and personal factors. Appendix 2 (available online at www.pulsus.com), provides the detailed answers from the respondents.

CCM training: Support from CCM program directors, CCM department chiefs and trainees' mentors during CCM training was perceived as being important. Lack of protected time or opportunities to become involved in teaching, research or administrative activities were perceived as barriers for many trainees. Suggestions to overcome these barriers included formal workshops, teaching sessions, integrated activities in the curriculum and more time to develop personal projects related to nonclinical tasks.

Extracurricular training or activities: Trainees believed that developing unique expertise and pursuing additional subspecialty or academic training may facilitate achieving career goals and successful employment. They mentioned that planning for such additional 
training would be made easier if the CCM departments would disclose their future needs to the trainees early during the program. The need for a formal certification or degree in research or administration was also deemed to be important. In fact, a significant proportion of respondents believed they did not have the experience or credibility to become involved in administrative tasks.

Work environment: The majority of respondents were concerned that there were an insufficient number of intensivist positions in proportion to the number of CCM trainees. They also believed that job opportunities that would allow for nonclinical protected time were lacking. They recommended a centralized database of available positions and increased advocacy to create additional dedicated CCM positions in intensive care units that currently are operating under 'open' staffing models (ie, no dedicated intensivist staffing). They suggested the creation of a system to allow for work-sharing with senior intensivists who are considering a progressive retirement.

Professional network: Networking with intensivists across the country was often mentioned as being important for career development. Several respondents proposed strategies to facilitate trainees' access to existing networks in critical care (notably in the domains of administration and research) and the creation of a trainees' network to advocate for their needs.

Personal factors: Motivation, interest and colleagues' support were regarded as personal factors that impact on career development in nonclinical activities.

\section{DISCUSSION}

Most of the trainees who responded to our survey expected to practice CCM in an academic centre performing mainly clinical work with some teaching and research activities. However, they perceived the support currently available to help them develop a career in each of these areas to be generally poor. In addition, the majority of respondents were concerned that the number of available intensivist positions may be inadequate to employ the number of CCM trainees currently enrolled in Canadian residency programs.

Most of our results are consistent with the sparse literature evaluating CCM trainees' expectations. For example, an American survey of pulmonary and CCM physician-scientists (5) also found that trainees were generally pessimistic about their ability to obtain an academic intensivist position. This survey also found that trainees' perceived their likelihood of obtaining an academic career to be associated with institutional research support and mentorship, which are facilitators also identified by our respondents. Similarly, in a survey of emergency physicians in Brazil, the majority (76.5\%) reported that their career pathway had been influenced by supervised activities or training outside of their formal program (6). Collectively, these findings, including our own, suggest that CCM training programs could be more proactive in developing mentorship support, especially for nonclinical academic activities.

Our results also highlight discrepancies between the high proportion of trainees who aimed to work in an academic position (53\% [96\% if we include those aiming to work in both settings]), as well as the proportion of time they estimated to ultimately work on academic, nonclinical tasks. Our survey highlights that the expectations of current trainees may not align with those of the academic departments. In the past, having additional subspeciality training was considered to be sufficient to obtain an academic position. However, academic critical care departments are increasingly recruiting clinician scientists, and most graduating residents will, therefore, require additional scholarly training to become competitive.

The respondents to our survey provided several actionable suggestions to help training programs meet their needs for career planning. Specifically, CCM departments should, where possible, disclose their recruitment needs and priorities to current trainees. A centralized database of available positions may increase transparency and help align the number of training positions with the needs of the work force. Trainees should be encouraged to become involved in critical care societies, associations, groups and networks because these were perceived to be important facilitators for career development and obtaining successful employment. As a follow-up to the survey results, a Canadian Critical Care Trainee Network was created, with the goals to represent trainees on a national level and to lead activities that contribute to career development. Program directors and residency program committees should strive for greater flexibility in the curriculum to include more formal teaching or rotations in nonclinical academic areas.

Our study, similar to all surveys, was limited by voluntary rather than mandatory participation. Our high response rate should minimize this potential for selection bias, but it remains possible that the nonrespondents would have had a different profile or provided alternative views. Second, the respondents may have answered the questions in a manner that they perceived to be socially acceptable instead of providing their own honest opinions. This could help explain why a majority of our respondents aimed to work in academic centres, yet only a minority planned to engage in nonclinical academic work. In addition, the participants may not recall all of the mentoring and career planning support that they already receive from CCM training programs. Finally, our survey evaluated perceptions of job opportunities, rather than an actual measure of the potential for intensivist employment in the Canadian health system. Therefore, the actual discrepancy between number of trainees and available jobs may not be as large as our respondents estimated.

\section{CONCLUSION}

Current CCM trainees perceived the amount of support they receive to help them achieve their career goals (mainly clinical work in academic centre with some nonclinical tasks) to be inadequate. CCM training programs should develop strategies to help address perceived deficiencies in career planning, mentoring and training in nonclinical academic domains.

ACKNOWLEDGEMENTS: The authors thank all Canadian CCM trainees for their generous participation in the survey.

DISCLOSURES: The authors have no financial disclosures or conflicts of interest to declare. All authors have provided permission to publish the manuscript. Dr John Marshall is the past President of the Canadian Critical Care Trials Goup. Dr John Granton is the past President of the Canadian Critical Care Society. Dr Damon Scales is the current program director at the University of Toronto.

\section{REFERENCES}

1. Leigh JP, Tancredi DJ, Kravitz RL. Physician career satisfaction within specialities. BMC Health Serv Res 2009;16:166.

2. Peets A, Ayas NT. Restricting resident work hours: The good, the bad, and the ugly. Crit Care Med 2012;40:960-6.

3. Kaplan LJ, Shaw AD. Standards for education and credentialing in critical care medicine. JAMA 2011;305:296-7.

4. Royal College of Physicians and Surgeons of Canada. CanMEDS: Better standards, better physicians, better care. $<$ www.royalcollege. $\mathrm{ca} /$ portal/page/portal/rc/resources/aboutcanmeds $>$ (Accessed April 23, 2013).

5. Weinert CR, Billings J, Ryan R, Ingbar DH. Academic and career development of pulmonary and critical care physician-scientists. Am J Resp Crit Care Med 2006;173:23-31.

6. Abreu-Reis P, Oliveira GC, Curtarelli de Oliveira A, et al. Extra-curicular supervised training at an academic hospital: Is 200 hours the threshold for medical students to perform well in an emergency room? World J Emerg Surg 2012;22:S1-12. 


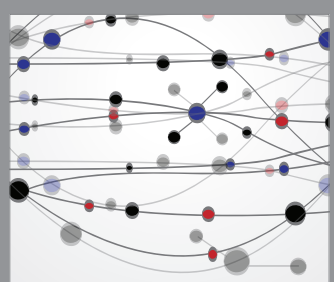

The Scientific World Journal
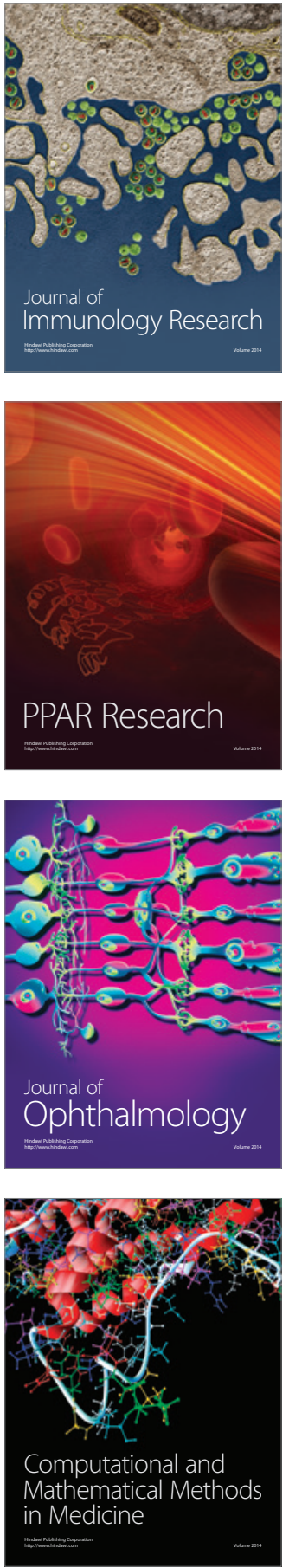

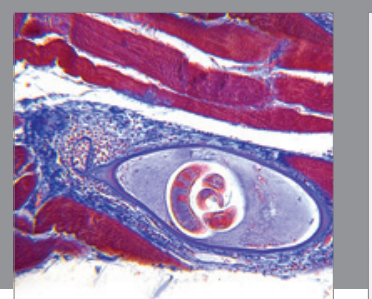

Gastroenterology Research and Practice

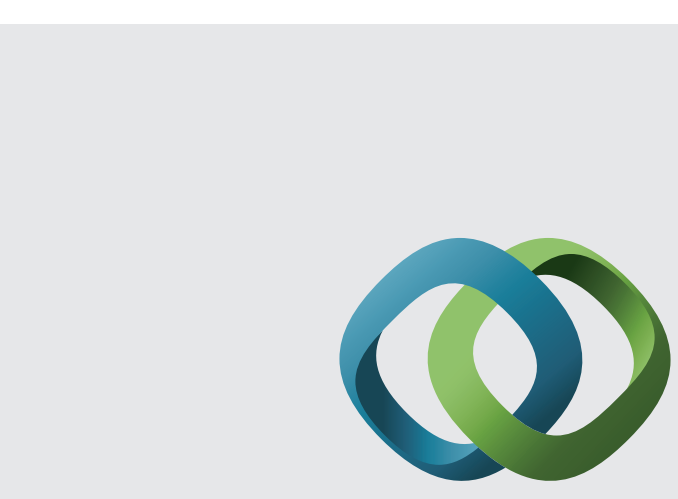

\section{Hindawi}

Submit your manuscripts at

http://www.hindawi.com
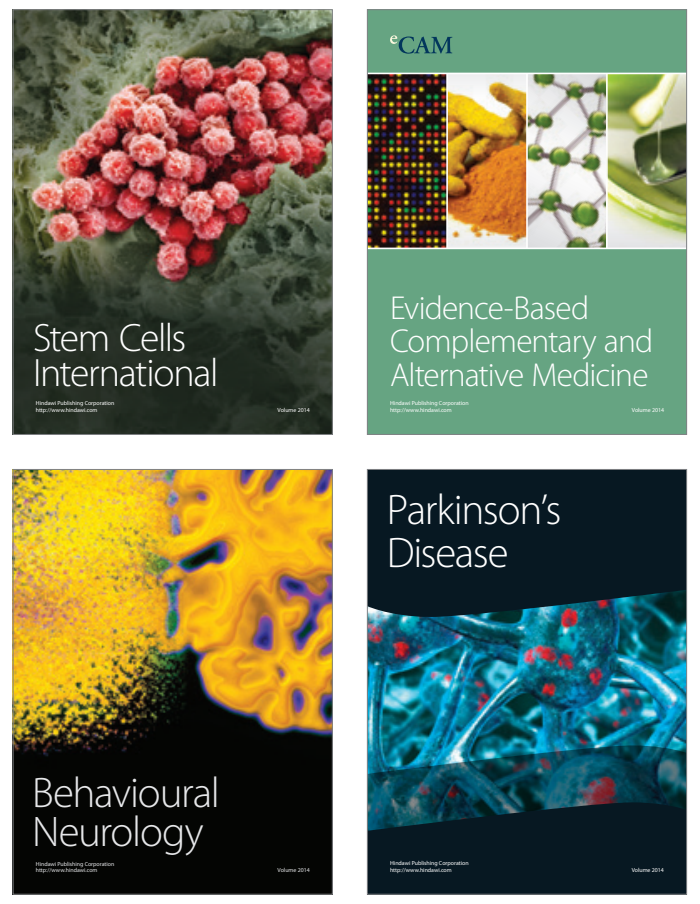
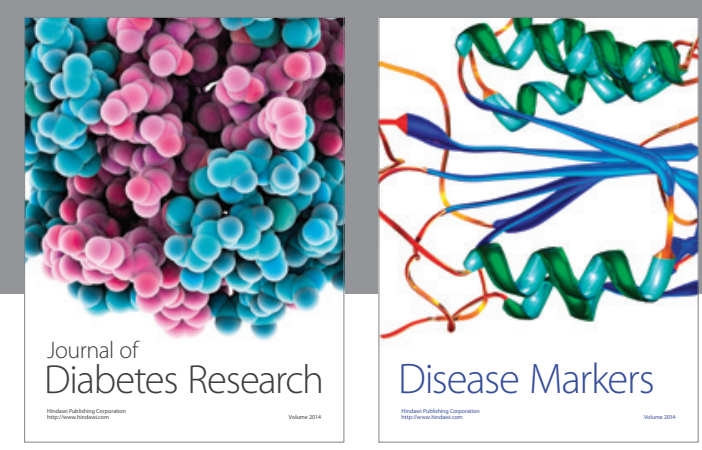

Disease Markers
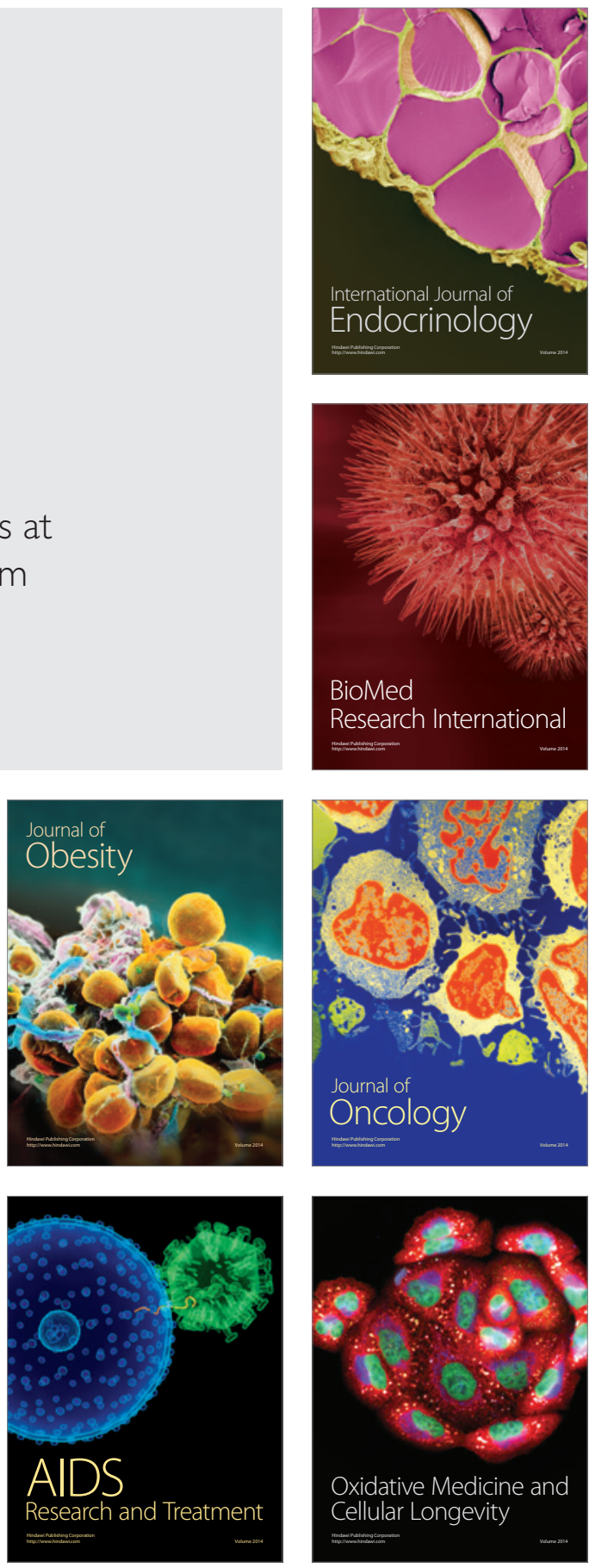